\title{
Double encephalitis with herpes simplex virus type II and cytomegalovirus in an elder Chinese: a case report
}

\author{
Chaobiao Xue ${ }^{1,2}$ \\ Shaoxian Chen' \\ Qi Lin' \\ Houshi Zhou' \\ Chuming Huang' \\ Jiyuan Lin' \\ Weihang Xie' \\ Kai Chen' \\ Dongming Zhou' \\ Wan $\mathrm{Ma}^{\prime}$ \\ Feiyu $\mathrm{Ma}^{\prime}$ \\ Haiyun $\mathrm{Xu}^{2}$ \\ 'Outpatient Department, Shantou \\ Central Hospital, Affiliated \\ Shantou Hospital of Sun Yat- \\ sen University, ${ }^{2}$ Mental Health \\ Center, Shantou University Medical \\ College, Shantou, Guangdong, \\ People's Republic of China
}

This article was published in the following Dove Press journal:

Neuropsychiatric Disease and Treatment

2 November 2015

Number of times this article has been viewed
Abstract: Herpes simplex encephalitis is a rare disease. In adults, most of the reported cytomegalovirus (CMV) infections are seen in immunocompromised patients. We present a case of 67-year-old Chinese male with the coinfection of CMV and herpes simplex virus type II (HSV-II). He had no history of being treated with immunosuppressants, showed symptoms of psychosis and was scored 109 on the Positive and Negative Syndrome Scale. This patient presented with a rare case of coinfection of CMV and herpes simplex virus type II with psychotic symptoms.

Keywords: brain, viral coinfection, psychotic symptoms

\section{Introduction}

Although herpes simplex virus (HSV) infections are very common worldwide, herpes simplex encephalitis (HSE) is a rare disease with an incidence of one case per 250,000-500,000 individuals per year. Approximately 50\% of patients with HSE are older than 50 years. ${ }^{1}$ Cytomegalovirus (CMV), another member of the herpesvirus family, is the most common cause of congenital infection, with a prevalence rate of $0.2 \%-2.5 \%$ in all live newborns. ${ }^{2,3}$ In adults, most reported CMV infections are seen in immunocompromised patients such as those with HIV (human immunodeficiency virus $)^{4,5}$ and after chemoradiotherapy. ${ }^{6}$ In these cases, the patients were also co-infected with HSV. Here, we present a patient with coinfection of CMV and HSV type II (HSV-II), who was admitted to the hospital for acute psychotic symptoms, but never treated with immunosuppressants before this admission.

\section{Case report}

For acute psychotic symptoms of delirium, delusion of persecution, fidget, over-alertness, and aggressive behaviors, a 67-year-old Chinese man was sent to the outpatient department of the Shantou Central Hospital, Guangdong province, People's Republic of China, on October 15, 2013. Three days before, the patient complained of headache. On October 14, he became suspicious, had delusion of persecution, and ran around. On the same day, he was sent to the local hospital where a magnetic resonance imaging was performed showing multiple hyperintensities in the left occipital lobe and temporal lobes in the T2-weighted images (Figure 1A). In addition, multiple hyperintensity lesions were seen in the temporal and parietal lobes and demyelination lesions in the white matter surrounding the lateral ventricles in the fluid-attenuated inversion recovery images (Figure 1B). Then, the patient was referred to the Shantou Central Hospital, Affiliated Shantou Hospital of Sun Yat-sen University on October 15. 

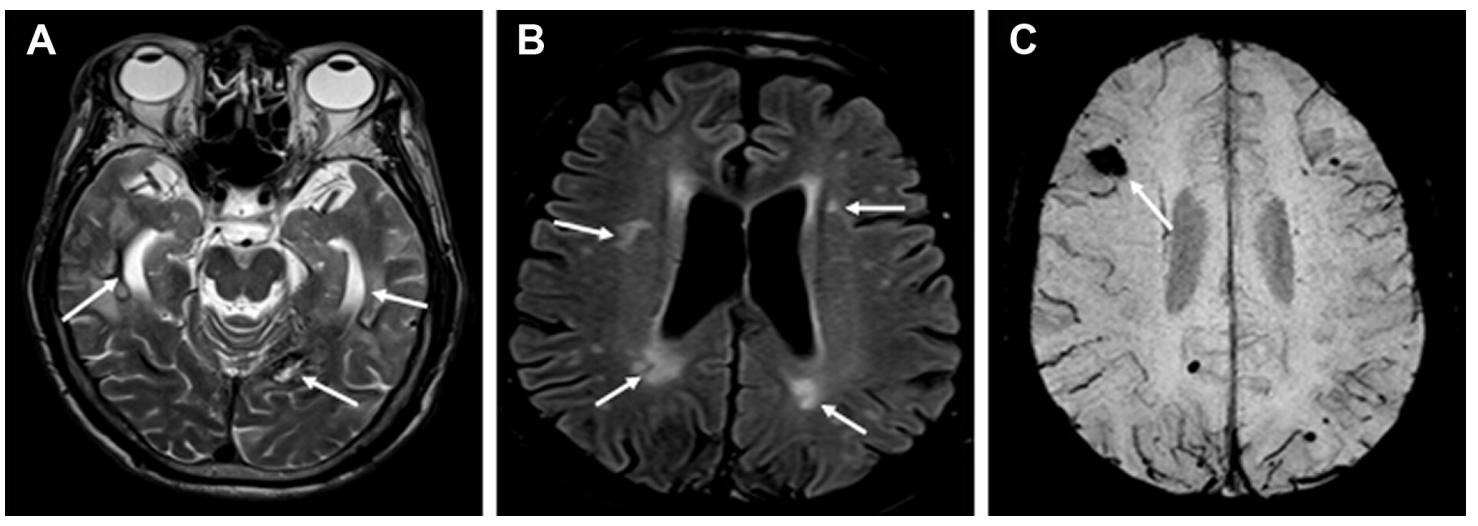

Figure I Magnetic resonance imaging of the patient's brain.

Notes: (A) A T2-weighted image showing hyperintensity lesions (arrows) in the temporal lobes and left occipital lobe. (B) Multiple hyperintensities (arrows) in the temporal and parietal lobes and demyelination in the white matter surrounding the lateral ventricles revealed by the fluid-attenuated inversion recovery sequences. (C) A susceptibilityweighted image showing a low signal (arrow) in the right frontal lobe.

On examination, the patient was somnolent and in the delirious state. But, physical examinations showed no abnormalities (normal blood pressure and there was no fever). There was no meningeal irritation sign and no Babinski sign on either sides. The Positive and Negative Syndrome Scale score was 109 (positive syndrome score of 36, negative of 14, and general of 59). The patient had no history of head trauma and hospitalization for mental disorders or any tumors, according to the family members.

Emergency treatment was started with the administration of the tranquilizer sodium phenobarbital $(100 \mathrm{mg})$ to reduce dysphoria and aggressive behaviors, the mood stabilizer sodium valproate ( $100 \mathrm{mg}$, administered in two fractions) to stabilize the mental state of the patient, and the antipsychotic olanzapine (10 mg, administered in four fractions) for the delusion of persecution. In addition, along with supportive treatments (piracetam 20 grams in $100 \mathrm{~mL} 0.9 \%$ sodium chloride), empirical administration of antiviral treatment (ganciclovir $250 \mathrm{mg}$ in $0.9 \%$ sodium chloride) was instituted under suspicion of viral encephalitis.

On October 16, a blood examination was performed which showed no anemia and leukocytosis, but presented a higher percentage of neutrophil number $(80.60 \%$; reference range $40 \%-75 \%$ ), a lower percentage of lymphocytes ( $11.70 \%$; reference range $20 \%-50 \%$ ), very high levels of creatine kinase (CK; $619 \mathrm{U} / \mathrm{L}$, reference range $0-174 \mathrm{U} / \mathrm{L})$ and its isoenzyme (CKMB; $39 \mathrm{U} / \mathrm{L}$, reference range 0-24 U/L). In addition, a higher level of C-reactive protein (CRP, 113 $\mathrm{mg} / \mathrm{L} ; 0-8 \mathrm{mg} / \mathrm{L}$ ) was found. No HIV antibodies were found. Chest radiographs (October 17) showed stale tuberculous lesions in the upper lobe of right lung.

On October 18, while the psychotic symptoms were improved, rough breath sounds were heard in the lungs, suggesting the presence of an infection there. Therefore, the antibiotic treatment with piperacillin-tazobactam $(4,500 \mathrm{mg}$ in $0.9 \%$ sodium chloride) was initiated while the other treatments continued. On the same day, an electroencephalogram was performed showing slow waves characterized by strong peaks of delta and theta frequencies in the frontal lobe of the right hemisphere (Figure 2). On October 19, a susceptibility-weighted imaging was performed, which more clearly showed the stale hemorrhages in the frontal lobe of the right hemisphere (Figure 1C), in addition to those seen in the left occipital lobe and temporal lobes of both sides.

The outcomes of cerebrospinal fluid (CSF) examination came out on October 20,21, and 22, respectively, showing blood cells in normal ranges, mild lower levels of chloride (117 $\mathrm{mmol} / \mathrm{L}$; reference range $120-132 \mathrm{mmol} / \mathrm{L})$, and glucose $(2.41 \mathrm{mmol} / \mathrm{L}$; reference range $2.8-4.5 \mathrm{mmol} / \mathrm{L})$. No bacteria were found. But both anti-CMV IgG and anti-HSV-II IgM were positive, supporting a diagnosis of coinfection with HSV-II and CMV in the brain. His body temperature

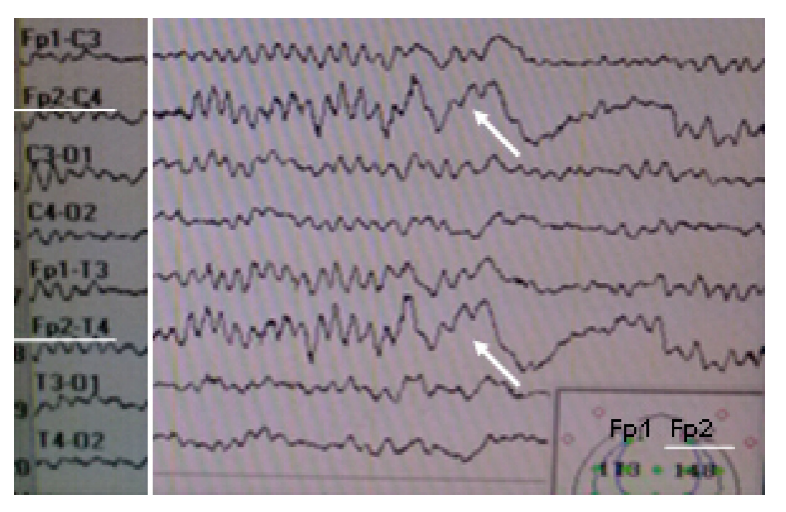

Figure 2 The electroencephalogram of the patient showing slow-waves characterized by strong peaks of delta $(\delta)$ and theta $(\theta)$ frequencies in the right frontal lobe. Note: The arrows point to slow-waves from the Fp2-C4 and Fp2-L4. 
was $37.3^{\circ} \mathrm{C}$. The antiviral and antipsychotic treatments continued.

On October 28, as required by the family members, the patient was discharged. His psychotic symptoms were significantly improved as evidenced by the reduction of Positive and Negative Syndrome Scale from 109 to 71 (positive syndrome score of 14 , negative of 13 , and general of 44).

The patient continued the antiviral and antipsychotic treatments at home after the discharge from the hospital. He died of progressive cachexia 4 months after the discharge (February 26, 2014), although his psychotic symptoms did not relapse. The patient's family members authorized the publication of his case. The ethics committee of the Shantou Central Hospital did not require approval for this case study.

\section{Discussion}

Except for one early case report, ${ }^{7}$ all other double infections of the central nervous system (CNS) with CMV and HSV were reported in immunocompromised patients. ${ }^{4-6,8}$ The patient reported here had no history of being treated with immunosuppressants. His blood examination showed normal cell count despite of the presence of anti-CMV IgG and anti-HSV-II IgM in CSF, which is in accordance with the reported evidence for increased production of antibodies against several neurotropic infectious pathogens including HSV-I, HSV-II, and CMV, in the CSF of individuals with bipolar disorder ${ }^{9}$ or autism spectrum disorders. ${ }^{10,11}$ The mild signs of CNS inflammation in this patient may account for the absence of seizures and focal neurological signs although he presented primarily acute psychotic symptoms and mental status changes. In line with this patient with HSV-II infection, neurological sequelae were more frequent among patients with HSV-I compared with those infected with HSV-II. ${ }^{12}$ In addition, CMV encephalitis in immunocompetent individuals has been associated with mild signs of CNS inflammation, including absent to moderate pleocytosis. ${ }^{13-15}$ In contrast, CMV in immunocompromised patients was featured with more severe clinical manifestations. ${ }^{5,6,16}$

The pathological hallmark of HSE is hemorrhagic necrosis in the medial part of the temporal lobes. In addition, adjacent areas such as the orbital surface of the frontal lobe and cingulate gyrus may be involved. In line with these, magnetic resonance imaging of this patient showed hemorrhages in multiple regions of the brain, including the right frontal lobe, left occipital lobe, and the temporal lobes of both sides. The hemorrhage in the right frontal lobe may be related to the peaks of delta and theta frequencies seen in electroencephalogram of this brain region. In addition, this patient showed multiple small infarctions and demyelination in the white matter surrounding the lateral ventricles. The multiple small infarctions may be the consequence of CMV infection. In line with this speculation, animal, and human studies ${ }^{17-20}$ have shown the CMV-induced damage of microvascular endothelium, vasculitis, thrombotic occlusions, and hemorrhages.

Another feature of this patient is a very high level of CRP in his blood. The co-existence of high CRP level and the antibodies to CMV and HSV-II reminded us of a recent human study, in which the CRP level was strongly associated with viral detection rate and mixed viral/bacterial detection rate; whereas the rate of bacterial detection was not associated with the CRP level. ${ }^{21}$ More significantly, plasma CRP was an independent predictor of mortality in patients with chronic obstructive pulmonary disease caused by virus infections. ${ }^{21,22}$

In summary, we present a case of a 67-year-old male with coinfection of CMV and HSV-II and without history of being treated with immunosuppressants. The presence of his psychosis symptoms and absence of neurological manifestations may represent the clinical features of coinfection of CMV and HSV-II.

\section{Disclosure}

The authors report no conflicts of interest in this work.

\section{References}

1. Lakeman FD, Whitley RJ. Diagnosis of herpes simplex encephalitis: application of polymerase chain reaction to cerebrospinal fluid from brain-biopsied patients and correlation with disease. National Institute of Allergy and Infectious Diseases Collaborative Antiviral Study Group. J Infect Dis. 1995;171:857-863.

2. Malm G, Engman ML. Congenital cytomegalovirus infections. Semin Fetal Neonatal Med. 2007;12:154-159.

3. González-Sánchez HM, Monsiváis-Urenda A, Salazar-Aldrete CA, et al. Effects of cytomegalovirus infection in human neural precursor cells depend on their differentiation state. J Neurovirol. 2015;21:346-357.

4. Vago L, Nebuloni M, Sala E, et al. Coinfection of the central nervous system by cytomegalovirus and herpes simplex virus type 1 or 2 in AIDS patients: autopsy study on 82 cases by immunohistochemistry and polymerase chain reaction. Acta Neuropathol. 1996;92:404-408.

5. Katchanov J, Branding G, Stocker H. Combined CMV- and HSV-1 brainstem encephalitis restricted to medulla oblongata. J Neurol Sci. 2014;339:229-230.

6. Suzuki HI, Hangaishi A, Hosoya N, et al. Herpes simplex encephalitis and subsequent cytomegalovirus encephalitis after chemoradiotherapy for central nervous system lymphoma: a case report and literature review. Int J Hematol. 2008;87:538-541.

7. Yanagisawa N, Toyokura Y, Shiraki H. Double encephalitis with herpes simplex virus and cytomegalovirus in an adult. Acta Neuropathol. 1975;33:153-164.

8. Laskin OL, Stahl-Bayliss CM, Morgello S. Concomitant herpes simplex virus type 1 and cytomegalovirus ventriculoencephalitis in acquired immunodeficiency syndrome. Arch Neurol. 1987;44:843-847.

9. Stich O, Andres TA, Gross CM, Gerber SI, Rauer S, Langosch JM. An observational study of inflammation in the central nervous system in patients with bipolar disorder. Bipolar Disord. 2015;17:291-302.

10. Gentile I, Zappulo E, Bonavolta R, et al. Prevalence of herpes simplex virus 1 and 2 antibodies in patients with autism spectrum disorders. In Vivo. 2014;28:667-671. 
11. Gentile I, Zappulo E, Bonavolta R, et al. Prevalence and titre of antibodies to cytomegalovirus and epstein-barr virus in patients with autism spectrum disorder. In Vivo. 2014;28:621-626.

12. Moon SM, Kim T, Lee EM, Kang JK, Lee SA, Choi SH. Comparison of clinical manifestations, outcomes and cerebrospinal fluid findings between herpes simplex type 1 and type 2 central nervous system infections in adults. J Med Virol. 2014;86:1766-1771.

13. Phillips CA, Fanning WL, Gump DW, Phillips CF. Cytomegalovirus encephalitis in immunologically normal adults. Successful treatment with vidarabine. JAMA. 1977;238:2299-2300.

14. Prosch S, Schielke E, Reip A, et al. Human cytomegalovirus (HCMV) encephalitis in an immunocompetent young person and diagnostic reliability of HCMV DNA PCR using cerebrospinal fluid of nonimmunosuppressed patients. J Clin Microbiol. 1998;36:3636-3640.

15. Studahl M, Ricksten A, Sandberg T, Bergström T, Elowson S. Cytomegalovirus encephalitis in four immunocompetent patients. Lancet. 1992;340:1045-1046.

16. Xu X, Bergman P, Willows T, et al. CMV-associated encephalitis and antineuronal autoantibodies - a case report. BMC Neurol. 2012; $12: 87$.
17. Foucar E, Mukai K, Foucar K, Sutherland DE, Van Buren CT. Colon ulceration in lethal cytomegalovirus infection. Am J Clin Pathol. 1981; 76:788-801.

18. Francis ND, Boylston AW, Roberts AHG, Parkin JM, Pinching AJ. Cytomegalovirus infection in gastrointestinal tracts of patients with HIV-1 or AIDS. J Clin Pathol. 1989;42:1055-1064.

19. Golden MP, Hammer SM, Wanke CA, Albrecht MA. Cytomegalovirus vasculitis. Case reports and reviews of the literature. Medicine (Baltimore). 1994;73:246-255.

20. Persoons MCJ, Stals FS, Van Dam Mieras MCE, Bruggeman CA. Multiple organ involvement during experimental cytomegalovirus infection is associated with disseminated vascular pathology. J Pathol. 1998;184:103-109.

21. Clark TW, Medina MJ, Batham S, Curran MD, Parmar S, Nicholson KG. $\mathrm{C}$-reactive protein level and microbial aetiology in patients hospitalised with acute exacerbation of COPD. Eur Respir J. 2015;45:76-86.

22. Lu S, Li T, Xi X, et al. Prognosis of 18 H7N9 avian influenza patients in Shanghai. PLoS One. 2014;9:e88728.
Neuropsychiatric Disease and Treatment

\section{Publish your work in this journal}

Neuropsychiatric Disease and Treatment is an international, peerreviewed journal of clinical therapeutics and pharmacology focusing on concise rapid reporting of clinical or pre-clinical studies on a range of neuropsychiatric and neurological disorders. This journal is indexed on PubMed Central, the 'PsycINFO' database and CAS,
Dovepress

and is the official journal of The International Neuropsychiatric Association (INA). The manuscript management system is completely online and includes a very quick and fair peer-review system, which is all easy to use. Visit http://www.dovepress.com/testimonials.php to read real quotes from published authors. 